\title{
Temporalidade e Interpretabilidade na Análise de Narrativas
}

\author{
Maria C.D.P. Lyra ${ }^{1, *}$, Anália K. R. Ribeiro ${ }^{2} \&$ Luciane DeConti $^{3}$ \\ ${ }^{1}$ Universidade Federal de Pernambuco, Recife, PE, Brasil \\ ${ }^{2}$ Instituto Federal de Educação, Ciência e Tecnologia de Pernambuco, Recife, PE, Brasil \\ ${ }^{3}$ Universidade Federal do Rio Grande do Sul, Porto Alegre, RS, Brasil
}

\begin{abstract}
RESUMO - Destacamos a importância de manter uma consistência vertical nos estudos que versam sobre narrativas para a compreensão da psique humana. Nessa direção, os princípios da temporalidade e sua íntima relação com a interpretabilidade, propostos por autores clássicos como Bruner, Polkinghorne, Ricoeur e Sarbin, são tomados como guias na manutenção dessa consistência. Para ilustrá-la, analisamos duas narrativas versando sobre temas diversos: experiência escolar e supervisão acadêmica em psicoterapia. Na primeira, os processos de segmentação e encadeamento do tempo engajado no mundo da ação constituem elementos-chave de análise na significação da experiência escolar. Na segunda, o interdiscurso entre a estagiária e a supervisora se interliga e cria significado pela própria inter-relação entre tempos narrativos diversos.
\end{abstract}

PALAVRAS-CHAVE: narrativa, significado, tempo, temporalidade, interpretabilidade

\section{Temporality and Interpretability:Analysis of Narratives}

\begin{abstract}
This paper highlights the importance of maintaining vertical consistence in narrative studies investigating human psyche. The principles of temporality and interpretability, proposed by classic authors as Bruner, Polkinghorne, Ricoeur e Sarbin, are taken as guidelines to maintain this consistence. To illustrate this idea, two narratives dealing with different themes are analyzed: one referring to school experience and the other to academic supervision of psychotherapy. For the first one the processes of segmentation and entanglement of the engaging time in the world of action compose the key-elements to analyze the meaning of school experience. For the second, different narrating times - one of the trainee and the other of the supervisor - create an interdiscourse from which meaning emerges as a consequence of the interrelationships of diverse narrating times.
\end{abstract}

KEYWORDS: narrative, meaning, time, temporality, interpretability

As narrativas são estudadas com diferentes propósitos sendo concebidas de diferentes maneiras. Em Psicologia, elas têm contribuído tanto nas pesquisas básicas (Bamberg, 2008; Brockmeier \& Carbaugh, 2000) quanto nas aplicadas (Gergen \& Gergen, 2004; Gonçalves, Matos, \& Santos, 2009; Grohs \& Sperb, 2011; Hermans \& Hermans-Jansen, 1995). Podemos conceber que a narrativa constrói, na esfera simbólica, significados de natureza eminentemente temporal que inserem a nossa experiência individual na história cultural (Bruner, 1986, 1989, 1997; Sarbin, 1986). Assim, o tempo construído na narrativa passa a ser o fio condutor da sua interpretabilidade, tal como nos propõem autores clássicos como Bruner (1986, 1989, 1997), Polkinghorne (1998), Ricoeur (1994, 1995) e Sarbin (1986).

\section{PRESENTETRABALHO}

O presente trabalho destaca a interdependência entre tempo e interpretabilidade como marcos da necessidade de manter uma consistência vertical em se tratando do estudo de narrativas. Essa consistência diz respeito à interdependência entre pressupostos ontológicos e epistemológicos, que alicerçam a teoria adotada, bem como

*E-mail: marialyra2007@gmail.com 
o método e a análise de dados, regendo o que é chamado de consistência vertical. Ela se aplica a quaisquer outros campos de estudo da Psicologia (Lightfoot \& Lyra, 2009; Lyra, 2007; Valsiner, 2006), além do estudo de narrativas. O que aqui destacamos é o papel, para o estudo de narrativas, desses dois princípios interdependentes - temporalidade e interpretabilidade - não os concebendo como originais nossos, mas visando resgatá-los como guias que possibilitem unificar a diversidade de perspectivas que hoje utiliza a abordagem narrativa para a compreensão da psique humana. Eles embasam uma diversidade de temas e/ou aspectos psicológicos investigados, como também diversas teorias. Por exemplo, adotando a perspectiva da teoria do self dialógico, Hermans e Hermans-Jansen (1995) analisam narrativas em psicoterapia, enquanto o trabalho de Spinillo e Martins (1997), de uma perspectiva cognitivista, analisa a coerência de narrativas em crianças. A consistência vertical requerida diz respeito a esses princípios e a adequação da teoria a eles, bem como, subsequentemente, ao método e à análise dos dados. Diferentes temas podem ser abordados e diferentes teorias adotadas (por exemplo, a psicanálise e o dialogismo), desde que todo o processo de investigação mantenha a consistência vertical acima referida.

Ilustramos essa compreensão através da análise de duas narrativas que tratam de temas diferentes, objetivos e modelos de análise distintos, mas mantêm uma consistência vertical com os princípios da temporalidade e sua íntima relação com a sua interpretabilidade.

\section{TEMPO COMO FUNDAMENTO DA INTERPRETABILIDADE: BRUNER E SARBIN}

Os princípios teóricos da perspectiva de análise em Psicologia que toma o tempo como historicidade e a interpretabilidade que dele decorre como fundamentos epistemológicos para a análise de narrativas respaldam-se nos trabalhos de Theodore Sarbin e Jerome Bruner. O primeiro advoga que a constituição narrativa do ser humano decorre da natureza temporal peculiar da humanidade, qual seja, de retomar os fatos em um tempo diferente de seu acontecimento. O segundo, busca superar, por meio da elaboração de princípios universais da narrativa, o relativismo que pode se insinuar nos estudos permeados de historicidade, caracteristicamente culturais e situados e, portanto, localmente diferenciados. Para Bruner, a ideia de um tipo peculiar de tempo narrativo se coloca com primazia nesses universais.

Para Sarbin (1986), o ato histórico, fundamentado na natureza temporal da experiência humana, põe no ato de narrar o locus da construção do significado dessa experiência.
A relação tempo e narrativa é assim resumida: “A percepção e experiência do tempo parecem ser um aspecto central de qualquer definição (de narrativa). Os conceitos de tempo e narrativa são intimamente relacionados" (Sarbin, 1986, p. 19). Bruner (1997), buscando superar a dicotomia entre generalizável e não generalizável, faz um esforço de abstrair, das particularidades de casos específicos, o que ele chama de nove universais das realidades narrativas. $\mathrm{O}$ primeiro universal explicitado por Bruner se refere ao tempo, ou melhor, a um tipo específico de tempo chamado de estrutura de tempo engajado, que é "um tempo que é delimitado não simplesmente pelos relógios mas pelas ações humanamente relevantes que ocorrem dentro de seus limites" (Bruner, 1997, p. 133). Esse tempo engajado é a base da natureza episódica da narrativa que, como veremos mais adiante, desempenha um papel importante na construção de significados.

\section{RELAÇÃO ENTRE TEMPO E NARRATIVA NA PERSPECTIVA DE PAUL RICOEUR}

Ricoeur $(1994,1995)$ expõe não apenas as bases, mas também os processos e as implicações da relação intrínseca entre tempo e narrativa. Essa relação é o foco inicial do terceiro capítulo do Tomo I do seu livro intitulado Tempo e Narrativa. Nesse, o autor, depois de ter explicitado sua perspectiva de tempo e de narrativa separadamente, demonstra como a narrativa e a temporalidade são dois processos indissociáveis que proveem a experiência humana de seu significado. Para Ricoeur, essa temporalidade pertence aos sistemas de significação da mediação simbólica, já que é um tempo vinculado ao dizer, aos atos humanos pertencentes à linguagem.

\section{Narrativa como Mimesis}

De Aristóteles, Ricoeur $(1994,1995)$ busca o conceito de narrativa como Mimesis da experiência. Para ambos, o conceito de Mimesis não é o de pura imitação, refere-se, antes, a um processo de criação e recriação da experiência na ação narrada. Nas suas palavras, "se continuamos a traduzir Mimesis por imitação, deve-se entender totalmente o contrário do decalque de um real preexistente e falar de imitação criadora" (Ricoeur, 1994, p. 76). Essa Mimesis se desdobra em três, que são mutuamente dependentes. A primeira, Mimesis 1, volta-se para a situação histórica e cultural na qual se deu a experiência entendida como o mundo da ação. A segunda, Mimesis 2, ocupa-se do enredo da narrativa. A terceira, Mimesis 3, procura compreender os processos de interpretação - ou refiguração do passado, sempre inacabado - presente na narrativa que possibilitam acompanhar, ao longo da história, os signficados que o narrador constrói em Mimesis 2 com base na pré-figuração que caracteriza a Mimenis 1 . 


\section{TEMPO E INTERPRETABILIDADE NA NARRATIVA DA EXPERIÊNCIA ESCOLAR}

A narrativa analisada foi escrita por uma estudante do curso de Eletrotécnica, na modalidade de Educaçao de Jovens e Adultos (EJA), no âmbito do Programa Nacional de Integração da Educação Profissional com a Educação Básica na Modalidade de Educação de Jovens e Adultos (PROEJA), em uma Instituçao Federal de Educação Profissional no agreste de Pernambuco. O PROEJA lida com um problema grave na educação brasileira, o abandono escolar ou as sucessivas retenções que terminam por gerar um exército de jovens e adultos pouco escolarizados e, consequentemente, com menores chances de serem incluídos nos processos sociais que dependem dos conhecimentos escolares. Entretanto, os problemas em torno da EJA não podem ser vistos, apenas, no que concerne à escola. Uma boa parte deles derivam dos contextos familiar e social. Os estudantes de EJA são atravessados por dramas familiares, de saúde e financeiros, entre outros, que desembocam no abandono da escola. Daí que a educação de jovens e adultos emerge como política pública que vai muito além de questões curriculares propriamente ditas. É preciso investigar as histórias dos estudantes, derivar seus significados, inferir os contextos e as relações neles postas.

O trecho da narrativa aqui analisada exibe esses atravessamentos. Quando solicitada a narrar de forma escrita a história da interrupção de sua trajetória escolar, a estudante remeteu-se a contextos para além da escola e trouxe para a narração o mundo da ação e suas relações nesses outros contextos mais amplos. Transcrevemos, abaixo, o trecho analisado da narrativa usando itálico.

Oi, sou Lúcia [nome fictício], mas me chamam de Lucinha. Moro desde de criança em Alagoinha, minha história é mais ou menos assim.

Comecei os estudos com seis anos fiz o primário até a terceira série, então parei por motivo muito triste. Ajudava minha mãe em casa com meus irmãos, depois de algum tempo ela veio a falecer, então fomos para São Paulo com meu pai (que eram separados) chegando lá, ele tinha outra pessoa e seis enteados então nós ficamos jogadas eu e minha irmã mais nova do que eu dois anos. Sofremos muito e além de tudo não podíamos estudar por falta de interesse dele, o meu pai.

Visando desvendar esse contexto extra-escolar, de cunho sociocultural amplo, recorremos a uma articulação entre a concepção de tempo engajado de Bruner (1977), especificamente no que concerne aos processos de segmentação e encadeamento construindo a interpretabilidade da narrativa, e Mimesis 1 de Ricoeur (1994), como pré-figuração da narrativa. Nessa articulação situamos e construímos nosso modelo de análise.
A Mimesis 1 é, aqui, destacada porque desempenha a primeira construção efetuada pelo tempo narrativo sobre a experiência. É nesse tempo engajado (Bruner, 1997) que o sujeito faz o primeiro recorte interpretativo dela, exibindo, assim, a sua íntima relação com o contexto sociocultural. Como primeiro nível de significação da narrativa, a Mimesis 1 - preservando a nomenclatura ricoeuroeuriana e chamando-a, a partir de agora, de mundo da ação - executa um recorte entre as várias possibilidades oferecidas pela sociedade onde ela se passa para definir o locus da experiência.

Em Mimesis 1, como compreensão pré-figurada da experiência no mundo, o sujeito seleciona cenários que compõem o mundo da ação. São esses cenários que estão presentes na construção do enredo, Mimesis 2. Esse primeiro trabalho é marcado por uma inscrição dessa compreensão em uma organização temporal na qual o sujeito segmenta e encadeia os elementos da ação, no contexto sociociocultural escolhido pelo narrador, para criar uma trama de significados que são trazidos na sua narrativa. Assim, o mundo da ação, tal como o narrador o compreende, apresenta-se no texto construído que, por sua vez, é desvendado no trabalho de compreensão - refiguração - realizado na Mimesis 3, que é, justamente, o trabalho interpretativo do leitor/ouvinte da narrativa e, também, do pesquisador.

Esse mundo da ação se apresenta no enredo narrativo na forma de três aspectos fundamentais: (a) natureza temporal; (b) trama conceitual; e (c) recursos simbólicos. A natureza temporal remete ao caráter episódico da narrativa, sua segmentação, assim como seu encadeamento. Isso significa que, enquanto forma um todo com começo meio e fim, a narrativa também comporta unidades menores, os episódios - chamados incidentes - que funcionam como elos em uma corrente. São, assim, unidades em si mesmas, mas, também, encadeiam-se formando o curso da ação narrada. A trama conceitual diz dos elementos tangíveis da história que são postos a funcionar conjuntamente, formando uma rede que dá, a cada elemento, significados que eles não carregam per si e a priori. Os recursos simbólicos são os meios pelos quais a narrativa possibilita avaliar ou justificar uma ação. Na Mimesis 1, a trama conceitual é tecida primeiramente dentro de cada incidente, desenhando, assim, os seus significados específicos. Constrói, dessa forma, uma característica especifica provida pelo papel que cada elemento da ação exerce na trama. Todavia, é através do trabalho de encadeamento que surge a tessitura que relaciona os incidentes, criando sentidos oriundos das articulações de cenários que, à primeira vista, não se relacionam entre si. Dessa forma, o modelo de análise aqui apresentado é organizado em duas etapas, segundo o tempo engajado de Bruner, segmentação e encadeamento, dentro dos quais são estruturados os 
elementos e processos apresentados por Ricoeur como constituintes da Mimesis 1.

Como parte da interpretabilidade buscada no processo de segmentação, situamos a identificação dos incidentes, suas tramas e seus recursos simbólicos. Um segundo nível de interpretabilidade é encontrado quando acompanhamos os significados providos pela análise do encadeamento desses incidentes. Desse jogo entre segmentação e encadeamento deriva-se uma síntese temporal superordenada que sintetiza como a narradora compreende o mundo da ação constitutivo da experiência escolar. É, justamente, nessa síntese que podemos identificar esse contexto sociocultural aqui referido como mais amplo que o escolar, justamente objeto de interesse da investigação efetuada.

\section{Procedimento de Análise}

Etapa 1 - Segmentação: Incidentes narrativos. Os incidentes narrativos são entendidos como: unidades temporais de significação dispostas sucessivamente na medida em que vão desvelando os acontecimentos mutuamente integrados como parte do todo narrativo. Cada uma dessas unidades é marcada por uma ação principal a que se agregam elementos da trama conceitual. O encadeamento dos incidentes retrata as transformações ocorridas no desenvolvimento da experiência. Cada nova unidade caracteriza um passo no desenrolar da experiência relatada, enfatizando, assim, os aspectos significativos para a história. (Ribeiro \& Lyra, 2008, p. 69)

A Tabela 1, que segue, apresenta a segmentação da narrativa, retomando-a na sua segmentação em incidentes analisados neste trabalho e contendo os marcadores temporais que os delimitam, destacados usando itálico. A Tabela 2, subsequente, apresenta esses incidentes e seus marcadores temporais [usando itálico] mas, também, a trama conceitual que os compõe e os recursos simbólicos que os avaliam. Após a apresentação da Tabela descrevemos como eles foram identificados e significados no processo de segmentação realizado pela narradora.

Tabela 1

Mimesis 1: incidentes narrativos

\begin{tabular}{cl}
\hline $\begin{array}{l}\text { Incidentes } \\
\text { narrativos }\end{array}$ & \multicolumn{1}{c}{ Excertos } \\
\hline Introdução & Oi, sou Lúcia, mas me chamam de Lucinha. Moro desde de criança em Alagoinha, minha história é mais ou menos assim. \\
\hline Incidente 1 & Comecei os estudos com seis anos fiz o primário até a terceira série, \\
\hline Incidente 2 & então parei por motivo muito triste Ajudava minha mãe em casa com meus irmãos, depois de algum tempo ela veio a falecer, \\
\hline Incidente 3 3 & $\begin{array}{l}\text { então fomos para São Paulo com meu pai (que eram separados) chegando lá, ele tinha outra pessoa e seis enteados então nós } \\
\text { ficamos jogadas eu e minha irmã mais nova do que eu dois anos. Sofremos muito e além de tudo não podíamos estudar por falta } \\
\text { de interesse dele, o meu pai. }\end{array}$ \\
\hline
\end{tabular}

Tabela 2

Mimesis 1: incidentes narrativos 1, 2 e 3, trama conceitual e recursos simbólicos presentes em cada incidente

\begin{tabular}{|c|c|c|c|}
\hline Elemento narrativo & Incidente 1 & Incidente 2 & Incidente 3 \\
\hline Marcadores temporais & com 6 anos & Então... depois de_algum tempo & Então... chegando lá... então, \\
\hline Ação principal & Comecei os estudos & Parei & não podíamos estudar \\
\hline \multicolumn{4}{|c|}{ Trama conceitual } \\
\hline motivo & & $\begin{array}{c}\text { por motivo muito triste, ela veio a } \\
\text { falecer }\end{array}$ & por falta de interesse dele, o meu pai \\
\hline circunstâncias & & $\begin{array}{c}\text { Ajudava minha mãe em casa com } \\
\text { meus irmão }\end{array}$ & $\begin{array}{l}\text { fomos para São Paulo nós ficamos jogadas eu e minha } \\
\text { irmã mais nova do que eu dois anos e além de tudo }\end{array}$ \\
\hline interação & & [minha mãe, meus irmãos] & $\begin{array}{l}\text { com meu pai [que eram separados] ele tinha outra pessoa } \\
\text { e seis enteados }\end{array}$ \\
\hline desfecho & $\begin{array}{l}\text { fiz o primário até } a \\
\text { terceira série }\end{array}$ & & \\
\hline Recursos simbólicos & & $\begin{array}{l}\text { por motivo muito triste [qualidade do } \\
\text { motivo] }\end{array}$ & $\begin{array}{l}\text { nós ficamos jogadas [das circunstâncias] } \\
\text { Sofremos muito }\end{array}$ \\
\hline
\end{tabular}

Cada incidente é marcado por uma ação principal que, do ponto de vista da linguagem, é assistida por uma rede de tempos verbais, advérbios e expressões de tempo em geral, aqui chamados de marcadores temporais. Estes funcionam como indicadores da circunscrição dos incidentes. Então, primeiramente identificamos os marcadores temporais, reconhecidos por nós como delimitando os incidentes. Por exemplo, a expressão desde de no trecho "Oi, sou Lúcia [nome fictício], mas me chamam de Lucinha. Moro desde de criança em Alagoinha, minha história é mais ou menos assim". E com seis anos, até a terceira série e então no trecho "Comecei os estudos com seis anos fiz o primário até a terceira série, então parei por motivo muito triste" 
A concepção de incidente como unidade mínima de análise torna a indicação da ação principal a tarefa concomitante e prioritária na sua identificação. Em alguns casos, na análise, é possível um agrupamento de ações, quando há um forte sentido de unidade entre elas e/ou quando algumas delas constituem apenas anúncios que se agregam a outras ações desdobradas no incidente.

O sentido de unidade de cada incidente torna perceptível as mudanças na qualidade das ações que formam a narrativa. Tais mudanças indicam o fechamento de um incidente e o início de outro. Essas mudanças são, geralmente, propiciadas por um fato novo ou por uma reorganização dos fatos da ação anterior relacionados ao tema geral da narrativa. Sendo a narrativa analisada um relato sobre a experiência escolar, essa passou a ser a referência para a identificação das ações de base de cada incidente. -

Como unidade básica de significação, cada incidente remete a uma ação específica na trama narrativa e fornece a ela um significado que inclui, mas também extrapola, os limites de sua especificidade. Após os incidentes, o próximo passo é a indicação da trama conceitual. Esta se refere aos aspectos tangíveis da história, como vimos, mas, também, ao entrelaçamento desses aspectos, colaborando para que os incidentes se mantenham relacionados na unidade maior que é o todo da narrativa. -

A trama conceitual remete a uma "compreensão prática" (Ricoeur, 1994, p. 89) da história narrada porque ela procura responder a questões como: Quem? Onde? Por quê? O quê? Como? Para quê? Com quem? Contra quem? (Ricoeur, 1994). Na narrativa, as respostas a essas questões são entrelaçadas e interdependentes. Elas correspondem a:

a) metas: uma ação implica finalidades, na medida em que há sempre uma ideia de futuro envolvida em nossas ações;

b) motivos: nós agimos movidos por crenças, desejos, intenções, convicções que impulsionam o fazer humano;

c) agente: não existe ação sem que um agente a tenha realizado, alguém atuou de alguma forma;

d) circunstâncias: uma ação não acontece isolada, ela está sempre inserida em suas circunstâncias;

e) interação: porque sociais, as ações sempre assumem um caráter relacional;

f) desfecho: uma ação é sempre levada a um sentido de fim, a um fechamento finalizador. (Ribeiro \& Lyra, 2008, p. 69)

A narrativa analisada implica articulação de signos, que são, por sua vez, públicos e sistêmicos. Disso deriva uma normatização da experiência humana construída como normas sociais que funcionam como recursos simbólicos, que garantem um reconhecimento da ação nas possibilidades éticas providas pela cultura. Esses recursos aparecem na narrativa por meio da avaliação e da justificativa. Ambas estão relacionadas aos aspectos éticos da ação que compõe a experiência. Assim, o comprometimento ético é parte integrante da negociação dos significados nas narrativas.

Ressaltamos que nem sempre todos os elementos da trama, ou os recursos simbólicos, são explicitados em cada incidente. Na Tabela 2 - que reproduz as palavras da narradora, acrescidas, entre colchetes, da inserção ou repetição de algumas palavras pelo pesquisador visando a clareza na compreensão do trecho - estão incluídos os marcadores temporais, a ação principal e da trama conceitual, o motivo, as circunstâncias, a interação envolvida e o desfecho, além dos recursos simbólicos.

Etapa 2 - Encadeamento dos incidentes no tempo engajado. Cada incidente representa uma unidade de significado constituída no tempo. O seu encadeando cria unidades superordenadas de caráter sintético que agrupam significados conjuntos, por dizer "maiores", que encadeiam toda a experiência narrada. A tarefa, então, consiste em abstrair da trama conceitual e seus recursos simbólicos, as características temporais inerentes a cada incidente para, em um segundo passo, compreender essas unidades superordenadas de caráter sintético.

Incidente 1. Delimita o início da experiência e também a sua interrupção precoce e funciona como um anúncio dos acontecimentos e como um prenúncio do que vem imediatamente a seguir, na ação do incidente 2 . O final dele ("fiz até a terceira série") e o início do incidente 2 ("então parei") se completam e, em certo sentido, são duas formas de relatar o mesmo fenômeno. Entretanto, o desfecho desse incidente ("fiz até a terceira série") se volta para a ação do incidente 1 ("comecei os estudos"), relatando o que foi realizado dessa ação. Já a ação do incidente 2 ("então parei") se volta para o que vai ser relatado e enfatiza a interrupção da experiência, não suas conquistas. É perceptível que, do primeiro para o segundo incidente, há uma mudança na qualidade do tempo da ação. É perceptível, também, pela forma como a narradora imediatamente traz o motivo da interrupção, que não são pequenas as proporções desse motivo nem a sua extensão na experiência.

Incidente 2. Marca uma ruptura radical com o incidente 1. Mistura-se, assim, a própria interrupção da experiência escolar com a memória pertinente ao incidente 1 , de um tempo definido pela casa da mãe e pela marca do cuidado e da cooperação recíprocas. Nele, a narradora é cuidada e é cuidadora. No incidente 2 ocorre, justamente, o desmonte dessa qualidade de tempo.

Incidente 3. Agora, a experiência da escola não é mais possível. A mudança geográfica radical do lócus onde a vida da narradora se desenvolve ("então fomos para São Paulo") e a mudança da companhia ("com meu pai") estabelece o contraste entre cuidado e abandono ("Ajudava minha mãe em casa com meus irmão" em contraposição a "nós ficamos jogadas eu e minha irmã mais nova"). É nessa qualidade de tempo, caracterizada pelo abandono, que acontece a ação do incidente 3 ("não podíamos estudar"). 
O significado dessa unidade de tempo é reforçado pelo motivo expresso pela narradora ("por falta de interesse dele, o meu pai").

A Tabela 3, que segue, demonstra os diferentes passos da análise do encadeamento como processo de significação.
Nela apontamos as características da qualidade temporal de cada incidente, assim como os definidores desse tempo, que se referem aos elementos da trama da ação dos quais derivam as características acima referidas. O tempo sintético e superordenado é explicitado por último.

Tabela 3

Mimesis 1: encadeamento dos incidentes no tempo engajado da narrativa

\begin{tabular}{cccc}
\hline Qualidade temporal & Incidente 1 & Incidente 2 & Incidente 3 \\
\hline Característica & Cuidado & Ruptura & Abandono \\
\hline $\begin{array}{c}\text { Encadeamento } \\
\text { dos incidentes }\end{array}$ & $\begin{array}{c}\text { Interação com a mãe } \\
\text { Experiência escolar } \\
\text { Alagoinha - casa da mãe }\end{array}$ & $\begin{array}{c}\text { Cessou a interação com a mãe }- \\
\text { morte da mãe } \\
\text { Interrupção da experiência escolar }\end{array}$ & $\begin{array}{c}\text { Interação com o pai (madrasta e enteados) } \\
\text { Não retomada da experiência escolar } \\
\text { São Paulo - casa do pai }\end{array}$ \\
\hline Definidores & Interação & Motivo & Interação \\
& Circunstâncias & Motivo \\
\hline
\end{tabular}

A partir dos significados que sintetizam a qualidade do tempo interno a cada incidente - cuidado, ruptura e abandono - procurou-se identificar como o encadeamento dessas qualidades do tempo engajado no seu processo de segmentação. Buscou-se, assim, encontrar no encadeamento entre os incidentes a construção de um significado maior. Esse significado diz de como os incidentes, postos a funcionar conjuntamente, dão conta de explicar como o contexto sociocultural mais amplo, externo à experiência escolar interfere nessa experiência.

Os significados da qualidade sintética da ordenação dos três incidentes analisados, cuidado $\rightarrow$ ruptura $\rightarrow$ abandono, fazem compreender o significado superordenado referido: comecei os estudos $\rightarrow$ parei $\rightarrow$ não podíamos estudar. A interconexão dessa sequência revela como a experiência escolar não é apenas definida pelo contexto escolar mas está imbricada em outros contextos. No presente caso, a organização da família da narradora aparece como determinante para o desenrolar da história da experiência escolar. Foi o contexto familiar que qualificou, por assim dizer, o tempo da narrativa da experiência escolar. Esse significado é superordenado àqueles de cada incidente per si.

Em síntese, na Tabela 3, apontamos as características da qualidade temporal de cada incidente, assim como os definidores desse tempo, que se referem aos elementos da trama da ação de que derivam as características acima referidas. O tempo sintético e superordenado é explicitado por último.

\section{Resumo do Processo de Análise}

Iniciou-se a análise a partir da compreensão da natureza episódica da narrativa, por meio da identificação dos incidentes. A identificação da trama conceitual, conservando a distribuição dos incidentes, possibilitou identificar como os elementos tangíveis do contexto histórico e cultural da experiência narrada são significados pela narrativa. A presença dos recursos simbólicos propiciou o reconhecimento de como a narradora avaliou e justificou as mudanças ocorridas na sua experiência. Por fim, emerge um tempo de caráter superordenado e sintético, que possibilita uma nova ordem de significação à narrativa estudada. Baseando-se no tempo narrativo, na sua natureza episódica e, mais especificamente, na construção mimética e superordenada dos significados da experiência narrada, foi possível compreender os processos de construção da experiência da narradora, ao conferir significado ao mundo da ação.

Em suma, a temporalidade específica da Mimesis 1, organizada como segmentação e encadeamento, fornece a base da interpretabilidade que, por sua vez, possibilita os significados inerentes à construção do enredo na Mimesis 2 , e, dessa forma, a compreensão reconfigurada desses significados na Mimesis 3.

\section{TEMPO E INTERPRETABILIDADE NA NARRATIVA DA PSICOTERAPIA}

Este modelo de análise parte das transcrições das entrevistas realizadas pela estagiária de Psicologia denominada Renata, com uma de suas pacientes, Andréia (nomes fictícios). Andréia tinha 10 anos quando foi atendida por Renata e estava em uma instituição de acolhimento porque foi encontrada com seus irmãos em situação de abandono, maus-tratos e negligência. Ambos os pais encontravam-se frequentemente alcoolizados, não conseguindo, portanto, 
exercer as funções básicas necessárias para com os seus filhos. Andréia é a irmã mais velha de seis irmãos e, segundo Renata, "se sabe que ela realizava todas as tarefas domésticas da casa, assim como cuidava de seus irmãos menores". Ela foi encaminhada para atendimento devido a um pedido seu e permaneceu em tratamento até voltar novamente para a casa parental, período este em que foi necessário interromper a psicoterapia. Renata e Andréia tiveram um total de dez sessões terapêuticas.

A narrativa descrita aqui é uma transcrição de uma das sessões de psicoterapia, concebidas como narrativas escritas que procuram descrever cada encontro terapêutico atravessado pelo olhar de seu narrador, no caso a estagiáriaterapeuta (De Conti \& Sperb, 2009, 2010). Essa estagiária, ao transcrever as entrevistas desenvolvidas com seus pacientes, buscou traduzir os acontecimentos (verbais, gestuais, visuais, táteis, auditivos, entre outros) presentes em cada entrevista para a linguagem escrita sob a forma de entrevista dialogada, de tal modo que esses acontecimentos se tornassem legíveis para o supervisor (meio receptor imediato). Esse material, bem como as questões e reflexões produzidas pela estagiária acerca do estágio como um todo, foram registrados pela terceira autora deste artigo no espaço da supervisão acadêmica.

Escolhemos a entrevista dialogada para compor este trabalho porque ela se constitui em um dos modos canônicos no acompanhamento da prática dos estudantes em estágio em Psicologia Clínica. Portanto, essas transcrições são narrativas, porque visam a uma rememoração da cronologia da entrevista. Essa memorização do desenvolvimento da entrevista permite uma reapropriação da experiência, ordenando-a. Colocar em ordem a experiência é temporalizála ou, como diz Ricouer (1994, 1995), é narrativizá-la, tendo como princípio organizador de sua sequencialidade a causalidade semântica.

Nosso foco de análise é, portanto, as intervenções da estagiária, visando a evidenciar o mundo pré-figurado da ação, ou seja, a Mimesis 1. Para isso, partimos de um intercruzamento das narrativas escritas pela estagiária sobre seus atendimentos com a reflexão acerca deles no espaço da supervisão acadêmica. $\mathrm{O}$ mundo da ação, utilizando a concepção ricoeuriana, pode ser entendido, primeiramente, a partir de duas perspectivas da natureza temporal: a do texto narrativo construído em cada sessão psicoterapêutica e aquela dos textos narrativos compostos ao longo das sessões. Essas duas temporalidades se interpenetram e podemos dizer que a segunda circunscreve a primeira. Ambas são delimitadas pelos recursos simbólicos, que compõem a teoria, fornecendo suporte às interpretações (justificativas, avaliações) feitas ao longo dos textos narrativos. Esses recursos dão corpo e sustentação ao enquadramento da práxis psicoterapêutica, e os denominamos aqui interdiscurso.

Já a trama conceitual ricoeuriana é composta pelo entrelaçamento desses níveis que são interdependentes.
Ou seja, diferente do primeiro modelo de análise, para compreendermos a lógica temporal que dá a uma narrativa específica (narrativa de uma sessão terapêutica) uma noção de todo com início, meio e fim, precisamos recorrer ao conjunto de narrativas produzidas por essa estagiária acerca dos atendimentos realizados com sua paciente. Temos aí a sobreposição das temporalidades narrativas. Contudo, além disso, foi necessário visualizarmos o interdiscurso presente em cada intervenção, permitindo, com isso, operarmos nesses mundos evidenciados, ressignificando-os. E, assim, compormos novas narrativas acerca dessas intervenções.

Nesse sentido, podemos dizer que foi necessário realizarmos uma investigação mais ampla que visou a construir uma ferramenta de análise do mundo da ação das intervenções constituídas pela estagiária de Psicologia em sua práxis psicoterapêutica. Vamos, então, ao modelo analítico. Esse modelo foi esboçado a partir das ideias elaboradas por Bertrand (1998), tendo como eixo principal a teoria de Ricoeur (1994, 1995). Nesse modelo, a Mimesis 1 explicita as condições da narrativa, ou seja, qual a compreensão do mundo da ação da qual parte a estagiária para dar forma às suas intervenções. Para isso, recorremos como fontes dos dados aos registros da supervisão acadêmica e aos apontamentos e observações descritos pela estagiária-terapeuta em suas narrativas escritas. A Mimesis 2 corresponde à composição narrativa propriamente dita, à tessitura da intriga. Nesse caso, nossas fontes de dados foram as próprias narrativas escritas. Por fim, a Mimesis 3 corresponde à refiguração do passado, entendido como a sequência inacabada e sempre aberta de suas reinterpretações. Nossa fonte dos dados foram as reflexões produzidas pela estagiária a partir da leitura de suas narrativas escritas acerca dos atendimentos articuladas à discussão das mesmas no espaço da supervisão acadêmica. Essa leitura e discussão permite, segundo Bertrand, que o autor se aproprie de sua produção narrativa e, com isso, se distancie da mesma, (re) configurando novos sentidos a partir dela.

Esse modelo é uma proposição para a análise do processo terapêutico como um todo. Como já dissemos anteriormente, neste artigo, deter-nos-emos à primeira etapa do processo, porém, esta, para ser evidenciada, depende da explicitação do texto narrativo, que, no nosso modelo, refere-se à Mimesis 2. Nessa formulação analítica, diferentemente do primeiro modelo de análise, para compreendermos o mundo da ação, foi preciso recorrer, como já colocamos acima, além do texto narrativo em si, às reflexões produzidas pela estagiária no espaço da supervisão acadêmica acerca de suas intervenções, as quais estão em parte registradas nas transcrições.

Nossa análise destaca dois aspectos enunciados no texto narrativo dessa estagiária: (a) o da intervenção feita explicitamente para sua paciente, o qual demarcamos no texto em itálico; e (b) o do enquadramento teórico que a estagiária faz acerca das ações de sua paciente e que registra no texto narrativo, o qual demarcamos com aspas (" "). 
Vamos então descrever uma das narrativas que nos propusemos analisar:

\section{Descrição da narrativa - Oitava Entrevista (A. paciente; R. terapeuta).}

[A. entrou na sala e logo viu a caixa nova em que colocamos as maquiagens. Incluímos algumas coisas como pulseiras, sombra...]

A.: Que é isso, deixa eu ver. [Olha tudo.] Coloca para mim a azul [sombra]. [Maquio A., ela se olha no espelho.] Bonito, passa o batom agora. Gostei! Não vou fazer as unhas hoje!

A.: Vou levar a caixinha para pintar as Barbies. [A. faz da pintura como bolsa e pega a caixa das Barbies.] Vamos vestir elas, tia? [Sentamos no chão. Me entrega uma Barbie e vai escolhendo as roupas que quer que eu coloque...] Olha, um bebê bem pretinho! [Também é novo! A. fica arrumando as bonecas, tem toda calma, colocando os enfeites novos...] Sabe onde elas vão hoje? R.: Onde?

A.: Ao baile!

R.: É mesmo, elas gostam bastante de ir ao baile.

A.: Hã, hã. [Depois de um tempo, A. coloca colares e pulseiras nela também e me entrega uma]. Eu sou sua mãe e você é minha filhinha. [A. coloca batom vermelho e se ajeita no espelho].

R.: Aonde eu vou ficar quando vocês forem no baile, já que sou sua filha?

A.: Vai junto, ora! [A. arruma e enfeita todas as Barbies. Tira todo o material da caixa de maquiagem e o organiza.] R.: A., você se dá conta que está organizando tudo de novo?

A.: E daí, eu gosto. [A. arruma tudo, guarda as Barbies.]

A.: Eu vou brincar de massinha de modelar! [Também nova. A. tira a azul para fora, mexe um pouco e a guarda.] Eu vou te ligar, tá? Só deixa eu fazer isso. [Pega a máquina de datilografar.] Quando fizer barulho, tu atende. [A. bate um tempo na máquina.] Tim...

R.: Alô!

A.: Oi mana, tudo bem?

R.: Tudo e você?

A.: Eu tenho um segredo para te contar, você não pode falar para ninguém. [Fala sussurrando.]

R.: O que foi mana? [Sussurro.]

A.: A mãe já teve um nenê.

R.: É mesmo?

A.: Eu descobri domingo.

R.: E como você descobriu?

A.: O juiz [ato falho], eu fui lá visitar ela na casa dela.

R.: E como estava o nenê?

A.: Eu não sei, quer dizer, eu bati na porta e não tinha ninguém lá. Mana, você pode vir para cá? Bem rápido, que eu quero te contar uma coisa.
R.: Está bem. [Levanto e vou perto da porta.] Tim, dom... A.: Oi mana. Quero te mostrar algo. [Procura a agenda.] Cadê aquela caixa de lápis? [Mudamos a caixa de lugar. A. a acha.] Escreve aqui para mim o que você gosta em mim?

R.: O que você quer que eu escreva?

A.: Ah R., escreve que você gosta de mim!

$\mathrm{R}$.: A., este tempo aqui é para falarmos sobre suas coisas [dar este suporte que está pedindo], falando de mim estaremos deixando de lado suas coisas!

A.: Eu começo, então. [A. escreve no papel que gosta do meu cabelo, das minhas unhas...]

R.: A., será que você quer que eu diga que gosto de você por medo de eu deixar de gostar se você me disser certas coisas? Você pode me falar qualquer coisa que eu vou estar com você, te gostando do mesmo jeito e te ajudando. [A. fecha a agenda, arrancando a folha do lado que havia escrito. Coloca a folha na máquina e a enrola.] A.: Deu certo!

R.: A., nosso tempo está acabando por hoje. Notei você bastante angustiada, com vontade de falar muita coisa e achando dificil.

A.: Sabe o que é, é que eu briguei com a tia do projeto hoje.

R.: É mesmo!

A.: Estou meio chateada!

R.: O que aconteceu? Podemos conversar sobre isso!

A.: Deixa pra terça que vem!

Obs.: “- O sintoma pode estar mascarando sua angústia, sua culpa.

- Entrar no jogo dela, no jogo modificar o seu sistema de funcionamento.

- Deixar ela mais solta, brincar.

- Ser sua mãe, dar colo, aquele carinho que não tinha.

- Deixar ela entrar naquilo que não tinha e não entrar tanto no real.

É brincadeira" [A. fala.]: pedido de não ser tão real.

- Intervenção: deixa eu ser mãe hoje; vamos deixar tudo bagunçado hoje".

Analisemos primeiro as intervenções. Uma das primeiras coisas que queremos destacar é a hipótese que Renata formula de que Andréia pode estar querendo que ela diga gostar dela por medo de que a terapeuta deixe de gostar dela caso mostre certas coisas. Que coisas podem ser essas? Renata expõe em supervisão acadêmica e, de certa forma, ela explicita isso na própria narrativa, que supõe que Andréia esteja tentando controlar a manifestação da sua agressividade e da sua revolta com tudo o que lhe aconteceu. Renata supõe, também, que sua paciente possa pensar ser culpada, devido suas atitudes e seus comportamentos, por "abandono" e "negligência" maternos, fatos a que Renata teve acesso antes de começar a atender Andréia. De certa forma, podemos dizer que essas informações acerca dos motivos que levaram 
Andréia ao acolhimento institucional permearam a leitura que Renata fez das atitudes de sua paciente, constituindo, assim, uma pré-compreensão dos atos de Andréia e configurando o seu mundo de ação (as intervenções). Essa suposição é que está permeando a intervenção de Renata. Essa intervenção introduz a versão de que pode existir algo que desagrade e que pode provocar que o outro não goste mais dela (a paciente). A partir dessa pré-compreensão das ações de Andréia, Renata intervém dizendo que há um espaço em que essas coisas podem se manifestar e que elas não modificarão o sentimento de gostar dela (da paciente).

Outro aspecto salientado por Renata em sua intervenção é a tentativa de Andréia em obter o controle de tudo, demonstrada no seu comportamento de organização e no seu pedido de que Renata escreva o que gosta nela. Essa tentativa de tudo controlar é vista por Renata como uma ação repetitiva de Andréia, explicitada em várias sessões. Aqui, além de visualizarmos uma continuidade narrativa que interpenetra diferentes sessões, compondo uma narratividade que perpassa as mesmas, também podemos evidenciar outro aspecto do mundo da ação de Renata, que delineia suas interpretações: a teoria que orienta a sua práxis psicoterapêutica, no caso, de orientação psicanalítica. Esse mesmo aspecto pode ser observado em outra intervenção de Renata, em que ela transforma o já falou muito de sua paciente em vontade de falar muita coisa, coisas que são difíceis para Andréia esboçar ("Notei você bastante angustiada, com vontade de falar muita coisa e achando difícil'"). Essa fala de Renata, como foi possível refletir em supervisão, foi articulada a partir de sua pré-compreensão de que Andréia se nega a falar certas coisas, que resiste em entrar no mundo de sentimentos conflitivos, ambivalentes, relativos, na concepção de Renata, à sua mãe. E essa leitura de resistência de Andréia em falar se sustenta também no arcabouço teórico que dá vida e movimento às intervenções de Renata.

É nesse mesmo arcabouço teórico que Renata interpreta falas de Andréia como ato falho e que "o sintoma [organizar tudo] pode estar mascarando sua angústia". É a partir dessa leitura que Renata interpreta as ações de Andréia e intervém a partir dessa pré-compreensão do mundo da ação. Essa análise evidencia o interdiscurso e a sobreposição das temporalidades narrativas. Há diversas vozes que se articulam em cada ação de Renata, cujo ato narrativo é testemunho de uma descrição de cena da experiência vivenciada por Renata em cada sessão. Mas, ao compor essas cenas narrativamente, mesmo que em uma narrativa delimitada pelo escopo de uma tentativa de transcrição cronológica da cena terapêutica, a mesma é re-transcrita, possibilitando à Renata reinterpretar sua própria ação. $\mathrm{Ou}$ seja, na análise desse texto narrativo, podemos visualizar dois discursos que se interpenetram, possibilitando evidenciar duas pré-compreensões que delimitam o mundo de ação de Renata: (a) a pré-compreensão da história de vida de sua paciente que configurou as suas intervenções com ela; e (b) a pré-compreensão teórica que delimitou as interpretações feitas por Renata acerca dos atos de sua paciente.

Esse modelo analítico permite compreender e visualizar a Mimesis 1, as pré-compreensões simbólicas que configuram o mundo da ação. Ele pode ser um instrumento de pesquisa, entre outros, para investigarmos e analisarmos a performance e a dinâmica terapêuticas. Como ferramenta analítica, tem um potencial interessante no trabalho com estagiários de Psicologia em sua prática psicoterapêutica, possibilitando ampliar o campo das reflexões acerca dos diferentes discursos que perpassam essa práxis.

\section{CONCLUSÃO}

Retomamos e destacamos, neste trabalho, os princípios da temporalidade e da sua íntima relação com a interpretabilidade, propostos por autores clássicos como Bruner, Polkinghorne, Ricoeur e Sarbin, para destacá-los como possíveis de guiarem uma consistência vertical - interdependência entre pressupostos ontológicos e epistemológicos-que alicerçam a teoria adotada, bem como o método e a análise de dados - nos estudos de narrativas que se voltam para a compreensão da psique humana.
Com esse propósito, foram analisadas duas narrativas que tratam de temas diferentes, objetivos e modelos de análise distintos, uma relativa à experiência escolar e outra à psicoterapia. Na primeira, o foco no mundo da ação Mimesis 1 - contribuiu com o desvendar de significados advindos de contextos socioculturais externos à experiência escolar mas que dela participaram e, na segunda, com novos horizontes na orientação de estagiários na clínica psicológica.

\section{REFERÊNCIAS}

Bamberg, M. (2008). Selves and identity in the making: The study of microgenetic processes in interactive practices. In U. Müller, J. Carpendale, N. Budwig, \& B. Sokol (Orgs.), Social life and social knowledge (pp. 205-224). Mahwah, NJ: Erlbaum.
Bertrand, M. (1998). Valeur et limites du narratif en psychanalyse. In M. Bertrand (Ed.), Psychanalyse et récit. Stratégies narratives et processus thérapeutiques (pp. 9-19). Besançon, France: Presses Universitaires Franc-Contoises. 
Brockmeier, J., \& Carbaugh, D. (2000). Narrative and identity: Studies in autobiography, self and culture. Amsterdam: John Benjamins.

Bruner, J. (1986). Actual minds, possible worlds. Cambridge, MA: Harvard University Press.

Bruner, J. (1989). Life as narrative. Social Research, 54(1), 11-32.

Bruner, J. (1997). Atos de significação. Porto Alegre: Artes Médicas. (Original publicado em 1990)

De Conti, L., \& Sperb, T. M. (2009). A composição de narrativas pela dupla terapeuta-paciente: Uma análise de sua organização e da sua sequência de ações. Psicologia: Reflexão e Crítica, 22, 119-127.

De Conti, L., \& Sperb, T. M. (2010). Praxis psicoterapêutica de estagiários de Psicologia: Análise do relato e da trama narrativa. Psicologia: Teoria e Pesquisa, 26, 305-314.

Gergen, K, J., \& Gergen, M. M. (2004). Social construction: Entering the dialogue. Chagrin Falls, $\mathrm{OH}$ : Taos Institute.

Gonçalves, M. M., Matos, M., \& Santos, A. (2009). Narrative therapy and the nature of "innovative moments" in the construction of change. Journal of Constructionist Psychology, $22,1-23$.

Grohs, G. H., \& Sperb, T. M. (2011). El texto narrativo en la clínica psicoanalítica del síntoma de aprendizage del lenguaje: Un análisis estructural. Diversitas (Bogotá), 7, 335-349.

Hermans, H. J. M., \& Hermans-Jansen, E. (1995). Self-narratives: The construction of meaning in psychotherapy. New York: Guilfoed Press.

Lightfoot, C., \& Lyra, M. C. D. P. (2009). Culture, development and the problem of vertical consistency. In C. Lightfoot \& M. C. D. P. Lyra (Orgs.), Challenges and strategies to study human development in cultural contexts (7-11). Roma: Firera \& Liuzzo Publishers.
Lyra, M. C. D. P. (2007). O modelo EEA: Definições, unidade de análise e possíveis aplicações. Psicologia: Reflexão e Crítica, 20(1), 87-95.

Polkinghorne, D. E. (1998). Narrative knowing and the human sciences. Albany: State University of New York Press.

Ribeiro, A. K., \& Lyra, M. C. D. P. (2008). O processo de significação no tempo narrativo: Uma proposta metodológica. Estudos de Psicologia (Natal), 13(1), 65-73.

Ricoeur, P. (1994). Tempo e narrativa (Tomo I, C. M. César, Trad.). Campinas: Papirus.

Ricoeur, P. (1995). Tempo e narrativa (Tomo II, M. Appenzeller, Trad.). Campinas: Papirus.

Sarbin, T. (1986). The narrative as a root metaphor for psychology. In T. Sarbin (Org.), Narrative psychology: The storied nature of human conduct (pp. 3-21). New York: Praeger.

Spinillo, A. G., \& Martins, R. A. (1997). Uma análise da produção de histórias coerentes por crianças. Psicologia: Reflexão e Crítica, 10(2), 219-248.

Valsiner, J. (2006). Developmental epistemology and implications for methodology. In D. William \& M. L. Richard (Orgs.), Handbook of Child Psychology (Vol. 1, pp. 166-209). Hobokem, NJ: John Wiley \& Sons Publisher.
Submissão: 16/05/2014

Revisão:16/05/2016

Aceite: 18/06/2018 